Research Article

\title{
Evaluation of Coupling Coordination among the Urban Physical Environment, Economy, and Population: A Case Study of 36 Main Cities in China
}

\author{
Min Chen, Zhihao Sun (D, Yuanjie Wang, and Shuaifeng Guo \\ School of Transportation and Civil Engineering, Nantong University, Nantong, Jiangsu 226019, China \\ Correspondence should be addressed to Zhihao Sun; 524439668@qq.com
}

Received 31 May 2019; Accepted 26 August 2019; Published 29 October 2019

Guest Editor: Mbakisya A. Onyango

Copyright (c) 2019 Min Chen et al. This is an open access article distributed under the Creative Commons Attribution License, which permits unrestricted use, distribution, and reproduction in any medium, provided the original work is properly cited.

\begin{abstract}
In the past three decades, about $0.93 \%$ of people moved from rural areas to cities per year in China. Therefore, understanding of the relationships among urban physical environment (UPE), economic development, and population growth are significant for China to realize sustainable urban development. Based on the concept and connotation of UPE and ecocity, the UPE evaluation system was constructed containing 6 first-level of indicators (i.e., climate, quality of ambient air and atmosphere, freshwater, wastewater, built environment, and noise pollution) and 13 second-level indicators. An entropy weight-TOPSIS model was developed in order to evaluate the UPE system, using the data of China's 36 main cities from 2003 to 2016. The coupling coordination degree (CCD) among the UPE, economy, and population was measured by a ternary CCD model. The results showed that (1) the UPE of 36 main cities showed periodic fluctuations throughout the 14 years, and the coastal cities and southern cities had superior UPE than the inland cities and northern cities, respectively; (2) the vast majority of cities' CCD had experienced steady upward trends. UPE, economy, and population promoted mutually in most of the cities, but in a few super cities, the economic development and population growth exceeded the capacity of UPE. Meanwhile, the CCD gaps between the northern and southern cities were significantly widened.
\end{abstract}

\section{Introduction}

At present, more than $50 \%$ of the world's population lives in cities, and the urbanization rate is expected to reach $60 \%$ by 2030 [1]. The modern society develops surrounding cities. In China, with the rapid urbanization, the urban population is expected to reach $80 \%$ in the next 20 years [2], and 13 15 million peasants will migrate to cities in the following each year [1]. China's urbanization rate is $59.58 \%$ in 2018 , in an accelerated developing state [3]. As the carrier of human survival and development, UPE bears tremendous pressure from rapid economic development and continuous population growth. Meanwhile, the quality of UPE affects people's migration decision $[4,5]$, and migration (immigration or emigration) successively affects the city's economic development (growth or and decline). The UPE, economy, and population system of the city constitute a complex social ecosystem, interacting with each other. Examining the relationships among the three systems are crucial for cities to achieve sustainable and healthy development. 36 main cities of China were taken as the study objectives which are of great regional influence, including 4 municipalities, 26 provincial capital cities, and 5 planned cities and Suzhou. It should be noted that Lhasa and Suzhou were two exceptions. Lhasa was excluded from the study cities because of the missing data in most years. In addition, Suzhou was selected because Suzhou is known as for "the most developed prefecture-level city in China," whose GDP is perennially in the top ten among all cities, surpassing most provincial capitals [6].

This research aims to fulfill three primary objectives. Firstly, we intend to construct the UPE indicator system basing on the concept of sustainable development. Secondly, we plan to develop a dynamic entropy weight-TOPSIS 
method to evaluate the UPE system of the cities being researched, revealing their dynamic trends and spatial distribution in the period of 2003-2016. Thirdly, this study aims to expound those cities' dynamic trend and spatial distribution of CCD among UPE, economy, and population basing on a ternary coupling model. The rest of the research was organized as follows: Data and methodology are focused on in Section 2 with data sources and preprocessing description, an improved TOPSIS method, and a triple CCD model. An evaluation index system of the UPE, population, and economy is constructed in Section 3. Evaluation results of both the UPE system and the CCD among three systems are given in Section 4. The conclusions and policy implications in this study are summarized in Section 5.

\section{Data and Methods}

2.1. Data Sources and Preprocessing. The required data of this study were collected from the China Statistical Yearbook, China Environmental Statistics Yearbook, China City Statistical Yearbook, China Agriculture Yearbook, and China Urban Construction Statistical Yearbook, and so on. The missing data were substituted by moving averages. In particular, due to the revision of the Ambient Air Quality Standard (GB3095-2012) by the Chinese Ministry of Environmental Protection in 2012, the monitoring method of pollutants has been changed, two indicators "Air quality" and "Airborne hazardous substances" being involved (Table 1). In order to maintain the comparability of the data before and after 2012, the two indicators were proceeded as follows: with regarding to the indicator "Air quality," we predicted the days of reaching secondary ambient air quality standard in 2012 basing on the data from 2003 to 2011, using the gray prediction method. The difference between the predicted value and the actual value was accepted as an adjustment value to adjust the data after 2012. As for the indicator "Airborne hazardous substances," the content value of PM10 with the changed monitoring method of 2012 has increased about 7\% according to relevant research [9], so the values of PM10 content from 2012 to 2016 were subtracted by $7 \%$ to ensure the comparability of the data.

\subsection{Research Method}

2.2.1. Dynamic Entropy Weight-TOPSIS Method. The steps are as follows, using the entropy weight method [10] to determine the weight of the indicators.

Firstly, normalize the indicators:

$$
\begin{aligned}
& \text { positive indicator, } r_{i j}^{+}=\frac{\left(x_{i j}-\min \left\{x_{j}\right\}\right)}{\left(\max \left\{x_{j}\right\}-\min \left\{x_{j}\right\}\right)}, \\
& \text { negative indicator, } r_{i j}^{-}=\frac{\left(\max \left\{x_{j}\right\}-x_{i j}\right)}{\left(\max \left\{x_{j}\right\}-\min \left\{x_{j}\right\}\right)},
\end{aligned}
$$

where $i$ is the evaluation object $(i=1,2, \ldots, m), j$ is the indicator $(j=1,2, \ldots, n)$, and $r_{i j}$ is the normalized value. $x_{i j}$ is the original value and $\max \left\{x_{j}\right\}$ and $\min \left\{x_{j}\right\}$ are the maximum and minimum values of the indicator $j$ of all evaluation objects.

Secondly, calculate the weights of indicators:

$$
\begin{aligned}
& \text { entropy value of indicator, } H_{j}=-\frac{\sum_{i=1}^{m}\left(r_{i j} / \sum_{i=1}^{m} r_{i j}\right) \ln \left(r_{i j} / \sum_{i=1}^{m} r_{i j}\right)}{\ln (n)}, \\
& \text { weight of indicator, } w_{j}=\frac{\left(1-H_{j}\right)}{\left(n-\sum_{j=1}^{n} H_{j}\right)} \text {. }
\end{aligned}
$$

After using the entropy method to determine the weight, the technique for order preference by similarity to the ideal solution (TOPSIS) will be applied to evaluate the relative merits of the evaluation objects. The traditional TOPSIS method orders the objects by ordering the distance between the evaluation object and the ideal solution (negative-ideal solution). The evaluation object will perform best while it has both the shortest distance from the ideal solution and the farthest distance from the negative-ideal solution, otherwise, perform worst. The distance between the evaluation object and the ideal solution (negative-ideal solution) is given as

$$
d_{i}^{ \pm}=\sqrt{\sum_{j=1}^{n}\left(f_{i j}-f_{j}^{ \pm}\right)^{2}},
$$

where $f_{i j}$ is equal to the normalized value of the indicator multiplied $w_{j}$ and $f_{j}^{ \pm}$is the ideal solution (negative-ideal solution).

The relative closeness $r c_{i}$ is taken as the basis of the TOPSIS ordering and calculated as follows:

$$
r c_{i}=\frac{d_{i}^{-}}{\left(d_{i}^{-}+d_{i}^{+}\right)} .
$$

Using the traditional TOPSIS method, the ideal solution and negative-ideal solution at different time points varied; therefore, it is only applicable to order the evaluation object at a certain time point, failing to reflect the time trend of the evaluation objects. So the TOPSIS method was improved by fixing the ideal solutions and negative-ideal solutions, respectively. Specifically, to a certain indicator, the arithmetic means of the maximum value (minimum value) during the study period is taken as the ideal solution (negative-ideal solution).

Then, the ideal solution can be calculated as

$$
b_{k j}^{+}=\left\{\begin{array}{l}
\max \\
\min
\end{array}\left(f_{1 j}(k), f_{2 j}(k), \ldots, f_{m j}(k)\right) .\right.
$$

If the indicator is positive, $b_{k j}^{+}=\max _{i} f_{i j}(k)$, otherwise, $b_{k j}^{+}=\min _{i} f_{i j}(k)$.

The negative-ideal solution is calculated as

$$
b_{k j}^{-}=\left\{\begin{array}{l}
\min \\
\max
\end{array}\left(f_{1 j}(k), f_{2 j}(k), \ldots, f_{m j}(k)\right) .\right.
$$

If the indicator is positive, $b_{k j}^{-}=\min _{i} f_{i j}(k)$, otherwise, $b_{k j}^{-}=\max _{i} f_{i j}(k)$, where $f_{i j}(k)$ represents the normalized 
TABLE 1: The UPE indicator system.

\begin{tabular}{|c|c|c|c|}
\hline First-level & Second-level & Description & Properties \\
\hline \multirow{4}{*}{ Climate } & Temperature & Consistency with the optimal temperature range & Positive \\
\hline & Humidity & $\begin{array}{c}\text { Deviation from the optimum humidity range } \\
\text { interval }\end{array}$ & Negative \\
\hline & Precipitation & Deviation from the equilibrium dryness index & Negative \\
\hline & Sunshine condition & Annual sunshine hours & Positive \\
\hline \multirow{2}{*}{ Quality of ambient air and atmosphere } & Air quality & $\begin{array}{l}\text { Days of reaching secondary ambient air quality } \\
\text { standard }\end{array}$ & Positive \\
\hline & $\begin{array}{l}\text { Airborne hazardous } \\
\text { substances }\end{array}$ & Content of PM10 & Negative \\
\hline Freshwater & Water resource & Water resources per capita & Positive \\
\hline Wastewater & Sewage treatment rate & $\begin{array}{c}\text { Actual volume of sewage treatment (i.e., industrial } \\
\text { wastewater and municipal wastewater) }\end{array}$ & Positive \\
\hline \multirow{4}{*}{ Built environment $[7,8]$} & Road & Urban road area per capita & Positive \\
\hline & Public transport & Number of buses per 10,000 people & Positive \\
\hline & Urban green level & Green coverage rate in built-up areas & Positive \\
\hline & Urban construction level & Proportion of built-up areas in urban areas & Positive \\
\hline Noise pollution & Noise & Equivalent sound level & Negative \\
\hline
\end{tabular}

value of the indicator and $k$ represents the year $(k=1,2, \ldots, N)$.

The new distance of the ideal solution (negative-ideal solution) $\bar{d}_{i}^{ \pm}(k)$ is defined as

$$
\bar{d}_{i}^{ \pm}(k)=\sqrt{\sum_{j=1}^{n}\left(f_{i j}(k)-\bar{f}_{j}^{ \pm}\right)^{2}},
$$

where $\bar{f}_{j}^{ \pm}=\sum_{k=1}^{N} b_{k j}^{ \pm} / N$ is the new ideal solution (negativeideal solution).

Lastly, the new relative closeness is calculated as

$$
\overline{r c}_{i}(k)=\frac{\bar{d}_{i}^{-}(k)}{\bar{d}_{i}^{-}(k)+\bar{d}_{i}^{+}(k)},
$$

where $\overline{r c}_{i}(k)$ is taken as the comprehensive score of the object $i$ in $k$ year.

2.2.2. CCD Model. The concept of "coupling" originated from physics, a process in which two or more elements mutually affect each other [11]. The CCD model is now widely used to measure the relationship between urbanization and eco-environment [12]. This study constructed a ternary CCD model to calculate the coordination degree among the UPE, economy, and population of 36 main cities.

Firstly, the coupling degree is denoted as

$$
C_{i}=\frac{\left(U_{i} \times V_{i} \times Z_{i}\right)}{\left(\left(U_{i}+V_{i}+Z_{i}\right) / 3\right)^{3}},
$$

where $U_{i}, V_{i}$, and $Z_{i}$ are the comprehensive scores of the three subsystems.

Lastly, CCD score $D_{i}$ can be calculated as follows:

$$
\begin{aligned}
D_{i} & =\sqrt{C_{i} \times E_{i}}, \\
E_{i} & =\alpha \times U_{i}+\beta \times V_{i}+\gamma \times Z_{i},
\end{aligned}
$$

where $E_{i}$ represents the level of effect of three subsystems and $\alpha, \beta, \gamma$ are the weights of the subsystems and $\alpha=\beta=\gamma=1 / 3$.

According to the scores of CCD, the degree of the coupling coordination among UPE, economy, and population can be divided into six development stages [13] as follows: $0.8<D \leq 1$, superiorly balanced development; $0.6<D \leq 0.8$, favorably balanced development; $0.5<D \leq 0.6$, barely balanced development; $0.4<D \leq 0.5$, slightly unbalanced development; $0.2<D \leq 0.4$, moderately unbalanced development; and $0 \leq D \leq 0.2$, seriously unbalanced development.

\section{The Indicator System of UPE, Economy, and Population}

3.1. The Indicator System of UPE. Quinn et al. [14] concluded that the UPE contained the physical structure and infrastructure of the city, including roads, buildings, parks, and so on. Diez Roux and Mair [15] pointed out that the UPE included not only traditional environmental exposures, such as air pollution but also various aspects of the manmade environment (e.g., land use and transportation, street design, urban design, and public space). Handy et al. [7] deemed that built environment comprises urban design, land use, transportation systems, and people's activities in these physical environments. The Bulletin of American Meteorological Society and the US Department of Agriculture believed that exploring the UPE contribute to improving people's living facilities with the use of vegetation, space, and structure [16]. Therefore, this study defines the UPE as the necessary material environment for urban residents to survive and develop, including the natural physical environment and artificial physical environment.

China's rapid urbanization in the past three decades has aggravated the conflict between environment and economy, population growth [17]. Therefore, the first-level indicator of UPE should be developed basing on the concept of sustainable development, covering the main aspects of the urban material 
environment which is essential to human activities. Firstly, four indicators (i.e., quality of ambient air and atmosphere, freshwater, wastewater, and noise pollution) were selected as the first-level indicators, referring to the categories of the environment index in International Urban Sustainability Indicators List (IUSIL) [18]. In addition, focusing on the material environment, some management indicators of the IUSIL were abandoned such as "Waste generation and management" and "Mechanisms to prepare and implement environmental plans." Secondly, climate and built environment were added as the first-level indicators. The reasons are as follows: climate reflects the physical characteristics of the atmosphere, affecting human activities. Climate change can indeed affect human migration, with which even the international mobility of the population changes [19]. Lu et al. [20] found that temperature changes had a significant positive impact on population migration in China. In summary, climate is an indispensable indicator of UPE. Finally, human activities in cities mainly occur in the man-made environment. Hence, the built environment should also be added to first-level indicators. In conclusion, the UPE indicator system was constructed with the six first-level indicators (i.e., climate, quality of ambient air and atmosphere, freshwater, wastewater, built environment, and noise pollution) (shown in Table 1).

The second-level indicators should be both representative and operative. Take the added indicators "Climate" as an example. Although most climate researches focus on temperature and precipitation [21], humidity and sunshine also affect human activities [22]. So the climate indicator in this study includes four second-level indicators, namely, temperature, humidity, precipitation, and sunshine. Firstly, the indicator of temperature should reflect the optimal temperature; we defined the degree of temperature coincidence $\gamma$ to evaluate the temperature and $\gamma=h /(h-H)$, where $h$ is the difference between the annual maximum temperature and the annual minimum temperature of every city; $H$ is the most comfortable temperature range referring to the China Ambient Air Quality Standards (GB3095-2012). Because the urban temperature ranges of all studied cities are large enough to cover the most comfortable temperature ranges, $\gamma$ can be set to a positive indicator. Secondly, since the optimal humidity varies from person to person, the optimal relative humidity of the human body should also be a range rather than a certain value. Peteris [23] claimed that the optimum humidity range of human perception is from $45 \%$ to $55 \%$; consequently, the offset value of humidity $L$ was defined to measure the humidity indicator, and $L=\sqrt{(x-a)^{2}+(x-b)^{2}}$, where $x$ is the annual average humidity and $[a, b]$ is the optimum humidity range for the human body. The greater the value of $L$, the greater the distance between the humidity of the city and the optimal humidity range; thus, $L$ is a negative indicator. Thirdly, we use the dryness index to measure whether a city's precipitation is suitable, for the suitable range of precipitation is difficult to be defined directly. When the amount of precipitation is greater than the amount of evaporation, the area is wet; otherwise, the area is dry. The balance of the precipitation and evaporation is accepted as the best dryness, and the value of the dryness will be 1 [24]. The dryness $K$ can be estimated by the formula $K=58.93 \times \sum(T / 12) / P$ $[25,26]$, where $P$ is the precipitation and $T$ is the biological temperature and $T \in(0,30)$. We finally use the deviation between a city's dryness index and value 1 to evaluate the precipitation indicator, which is a negative indicator. At last, the indicator of sunshine condition is represented by the annual sunshine index. Considering that the longer the sunshine time, the better for plant growth and solar energy utilization, the indicator is set to be positive.

\subsection{The Economic Indicator System and Population Indicator} System. The economic indicator system and the population indicator system used in this study refer to the previous study [27, 28]. The economic indicator system contains 4 first-level indicators being divided into 10 second-level indicators (i.e., GDP, fixed asset investment, total retail sales of consumer goods, per capita GDP, percentage of secondary industry in GDP, actual utilization of foreign capital, percentage of tertiary industry in GDP, GDP growth rate, productivity of total industry employed persons, and per capital value-added of tertiary industry) (See Table 2). The population indicator system consists of total population and number of employees (See Table 2).

\section{Results and Interpretations}

\subsection{Evaluate Results of UPE}

4.1.1. Time Trends of UPE. The weights of the indicators were calculated by the entropy weight method (see Supplementary Materials (available here)). The first-level indicators were sorted according to the weights with the following results: climate $(27.0 \%)$, built environment $(25.8 \%)$, freshwater $(16.6 \%)$, quality of ambient air and atmosphere $(14.6 \%)$, noise pollution $(8.8 \%)$, and wastewater (7.3\%). Climate had the highest weight and was the most influential factor at the first level. The second influential factor was the built environment. These two factors occupied $52.8 \%$ of the total impact. The entropy weight-TOPSIS method was used to calculate the evaluation scores of the UPE system (see Figure 1 and Supplementary Materials). Kunming had the highest average score of 0.607 among all cities from 2003 to 2016, and Lanzhou had the lowest average score of 0.328 . The five cities with the most superior UPE were ranked by the average score: Kunming, Haikou, Shenzhen, Xiamen, and Nanning, meanwhile, with the worst UPE five cities Lanzhou, Zhengzhou, Xi'an, Taiyuan, and Harbin in turn. Figure 1 showed that the evaluation scores of 36 main cities generally revealed upward trends in the long term but fluctuations in the short term during the study period. Further comparison of the values of indicators showed that the rising trends of UPE were mainly caused by the improvement of the built environment and air quality. With regard to the built environment, the value of "The proportion of built-up areas in urban areas" and "per capita urban road area” was growing rapidly from 2003 to 2016. These results can be considered as the consequence of rapid 
TABLE 2: Economic indicator system and population indicator system.

\begin{tabular}{|c|c|c|c|c|}
\hline Subsystem & First-level & Second-level & Description & Properties \\
\hline \multirow{10}{*}{ Economy } & \multirow{4}{*}{$\begin{array}{l}\text { Economic } \\
\text { aggregates }\end{array}$} & GDP & $\begin{array}{l}\text { The total market value of all final products and } \\
\text { services produced within one year }\end{array}$ & Positive \\
\hline & & Fixed asset investment & $\begin{array}{c}\text { The accumulation of physical assets such as } \\
\text { machinery }\end{array}$ & Positive \\
\hline & & Total retail sales of consumer goods & $\begin{array}{l}\text { The volume of physical transaction and the } \\
\text { service revenue }\end{array}$ & Positive \\
\hline & & Per capita GDP & $\begin{array}{c}\text { GDP divided by the household registered } \\
\text { population }\end{array}$ & Positive \\
\hline & \multirow{3}{*}{$\begin{array}{l}\text { Economic } \\
\text { structure }\end{array}$} & Percentage of secondary industry in GDP & $\begin{array}{l}\text { The added value of the secondary industry } \\
\text { divided by GDP }\end{array}$ & Positive \\
\hline & & Actual utilization of foreign capital & $\begin{array}{c}\text { The actually received foreign capital within one } \\
\text { year }\end{array}$ & Positive \\
\hline & & Percentage of tertiary industry in GDP & $\begin{array}{l}\text { The added value of the tertiary industry divided } \\
\text { by GDP }\end{array}$ & Positive \\
\hline & Economic growth & GDP growth rate & $\begin{array}{l}\text { Annual growth rate of GDP calculated at } \\
\text { comparable prices }\end{array}$ & Positive \\
\hline & \multirow{2}{*}{ Economic benefit } & $\begin{array}{c}\text { Productivity of total industry employed } \\
\text { persons }\end{array}$ & GDP divided by the number of total employees & Positive \\
\hline & & Per capital value-added of tertiary industry & $\begin{array}{l}\text { The added value of the tertiary industry divided } \\
\text { by the total population }\end{array}$ & Positive \\
\hline \multirow[b]{2}{*}{ Population } & & Total population & \multirow{2}{*}{$\begin{array}{l}\text { Household registered population } \\
\text { The number of the population participating in } \\
\text { economic activity }\end{array}$} & Positive \\
\hline & & Number of employees & & Positive \\
\hline
\end{tabular}

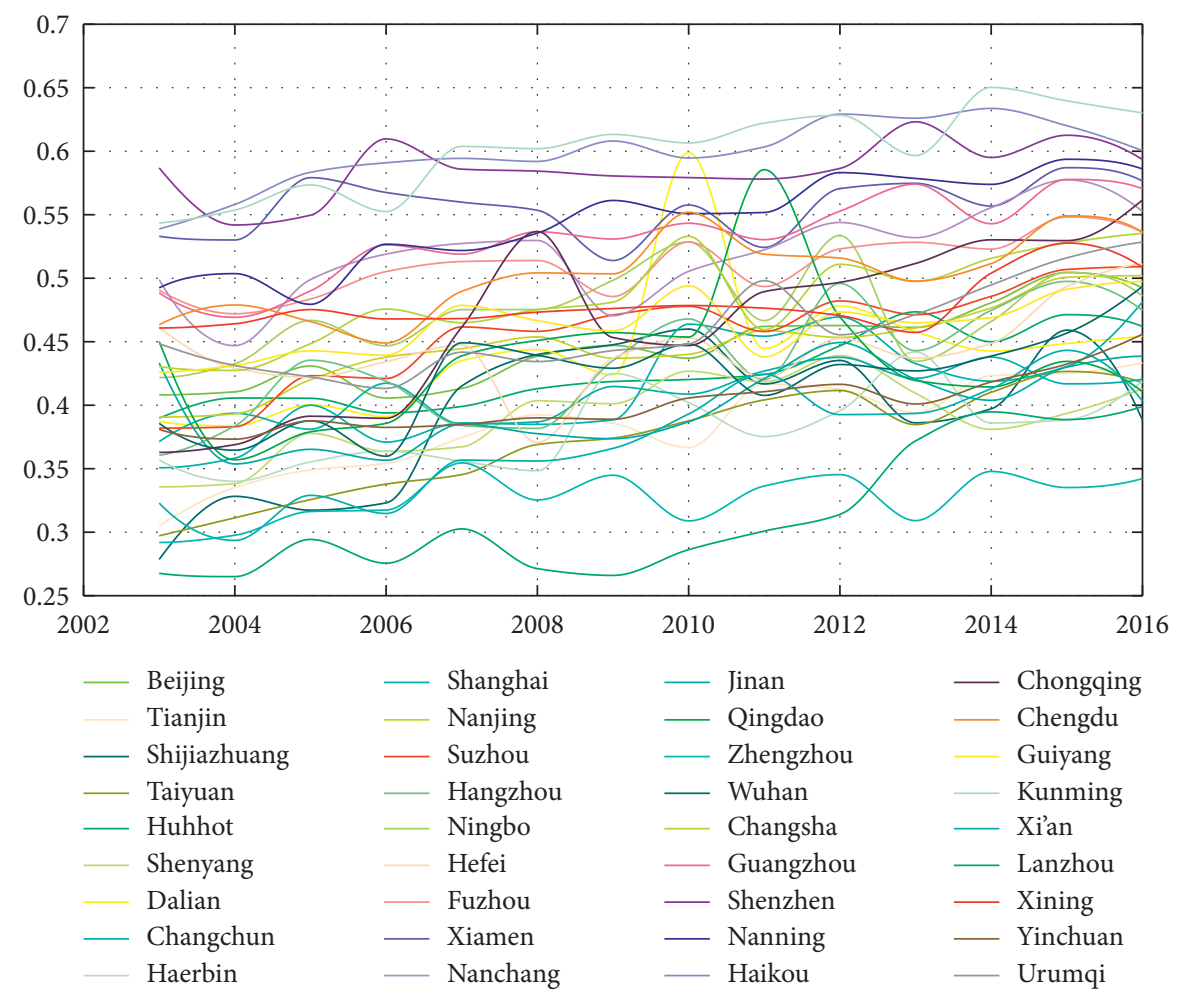

FIgURE 1: Trends of comprehensive levels of 36 main cities' UPE system.

urbanization and industrialization in China. In fact, most of the cities have experienced unprecedented expansion, and the total urban built-up land area expanded by about 7 times in the past three decades [29]. As for the air quality, China issued the Environmental Air quality Standard (GB30952012) in 2012 and the Action Plan for Air pollution
Prevention and Control in 2013, recommending to strengthen the monitoring of urban air quality and to significantly reduce the number of inhalable particles. Therefore, after 2013, the air quality improved significantly, presented as the increasing of the reaching secondary ambient air quality standard days and the decreasing of the 
PM10 content. In addition, the periodic fluctuation of the UPE primarily attributes to the instability of the climate, with the humidity, precipitation, sunshine, temperature all in fluctuating states. Although the causes of climate instability are still unclear, it is prone to be related to climate warming [30].

The UPE of 36 main cities generally improved rapidly, but a few cities had relatively large fluctuations such as Dalian, Qingdao, and Hefei. Firstly, the UPE score of Dalian increased sharply in 2010 primarily because the average precipitation in Dalian increased by $23.9 \%$, as water resources per capita increased nearly four times in 2009 compared to the previous year. Meanwhile, the appropriate humidity index rose from the 10th place in 2009 to the 1st place in 2010. Secondly, the UPE score of Qingdao also increased sharply in 2011, while the reasons were different. The UPE improvement of Qingdao, mostly due to several much-improved indicators, for example, temperature and humidity of Qingdao, tended to be optimal, the number of per capita buses increased, and the content of PM10 decreased. All these phenomena occurred simultaneously in 2011 , leading to a duplicate effect. Finally, the UPE of Hefei undoubtedly showed a downward trend in 2008. The cause may be that the Hefei government committed to building a strong industrial city in 2007 . Thus, the number of industrial enterprises increased by more than 500 in 2008 [31], leading to the deterioration of some indicators in the year of 2008 . For example, the days of reaching the secondary ambient air quality standard dropped sharply with the ranking dropping from the second to the last, and the ranking of the harmful substance content fell to the fourth from bottom.

In order to deeply compare the improvement of the 36 cities' UPE during the study period, the rankings of 36 main cities' UPE scores in both 2003 and 2016 are plotted in Figure 2. The cities with greater improvement were Chongqing and Suzhou, while Qingdao had the largest decline. From 2003 to 2016, Chongqing's UPE score had the largest amplitude, jumping from the 25 th place to 7 th. The indicators of "Urban construction level," "Urban green level," and "Air quality" played key roles in the ranking change. During the study period, Chongqing's urban builtup area increased by 906 square kilometers, the green space coverage rate increased by $22.9 \%$, and the days of reaching the secondary ambient air quality standard reached 195 days. As one of the four municipalities directly under the central government, Chongqing has developed rapidly in the past 20 years after the direct administration. The city scale was keeping expanding, with the rapid growth of the built-up area and the increase of urban green coverage. Suzhou was the second-biggest riser, moving up 9 places to 15 th mainly due to the decline of airborne hazardous substances. Suzhou issued a document in 2006, announcing the phasing out of backward production capacities, mainly relating to those industries which exert greater pressure on the environment, such as coal, petrochemical, and building materials industries. Thereafter, the emission of waste gas and discharge of industrial wastewater were reduced, and the air quality and water environment quality were obviously improved consequently. Qingdao was the city with the biggest drop in the ranking of UPE and dropped from 20th place in 2003 to 32 nd in 2016. This result may be explained by the fact that noise pollution of Qingdao increased by 6.76 decibels in 14 years, much higher than other study cities. Compared with other cities, Qingdao urgently needs to strengthen the noise pollution control.

4.1.2. Spatial Distribution of UPE. To reveal the geographical distribution of UPE, the spatial distribution maps of the 36 main cities' UPE in 2003 and 2016 are shown in Figure 3 and 4. In general, the coastal or riverside cities had higher UPE scores than those cities of inland. This means that the cities located in the coastal areas (e.g., Guangzhou, Shenzhen, Fuzhou, Xiamen, and Haikou) and the cities along the Yangtze river (e.g., Nanchang, Wuhan, Changsha, and Chengdu) have more superior UPE. Secondly, there were notable differences between the northern and southern urban agglomerations, and the UPE scores of the southern cities were higher than northern cities in general. Moreover, the high-scoring urban agglomerations were more concentrated in the south in 2016 than in 2003, while a small number of northern cities' UPE scores even declined, such as Jinan, Qingdao, Xining, and Yinchuan.

There are several possible explanations for this result. Firstly, the winter weather is cold in northern China, accompanied by the dry climate and big temperature gap, resulting in the low scores of the climate indicator. Secondly, the air quality of northern China is poor. On the one hand, sandstorms occur frequently because of the low coverage of surface vegetation and grassland desertification; comparatively, coal-fired heating and thermal power generation were widely used in northern cities which exacerbate air pollution [32]. In contrast to the northern cities, southern cities' UPE were relatively better. The results may be explained by the following facts. Most of the southern cities are located in the frontier area of reforming and opening-up and experienced the rapid expansion of the built environment; simultaneously, the climate condition of southern cities are better than the northern cities with warm and humid climate and rich precipitation as well. Furthermore, because of the high precipitation, suspended particles are not easy to float in the air, leaving the air quality generally better than that of the north.

\subsection{CCD among UPE, Economy, and Population}

4.2.1. Time Trends of the CCD. The results of CCD among UPE, economy, and population of 36 main cities are shown in Figure 5. During the study periods, the CCD of 36 main cities demonstrated overall increasing trends, and the average CCD score of each city was 0.467 . The evolution of the CCD system appeared to have two distinct time periods. Before 2009, most of the cities conformed to the "unbalanced development" stage. Afterward, most of the cities moved to the "balanced development" stage. From 2003 to 2008, only five cities achieved the "favorable balanced development" stage. Most of the other cities' CCD scores were between 0.4 and 0.6 ; in other words, they were in the phase of "barely 


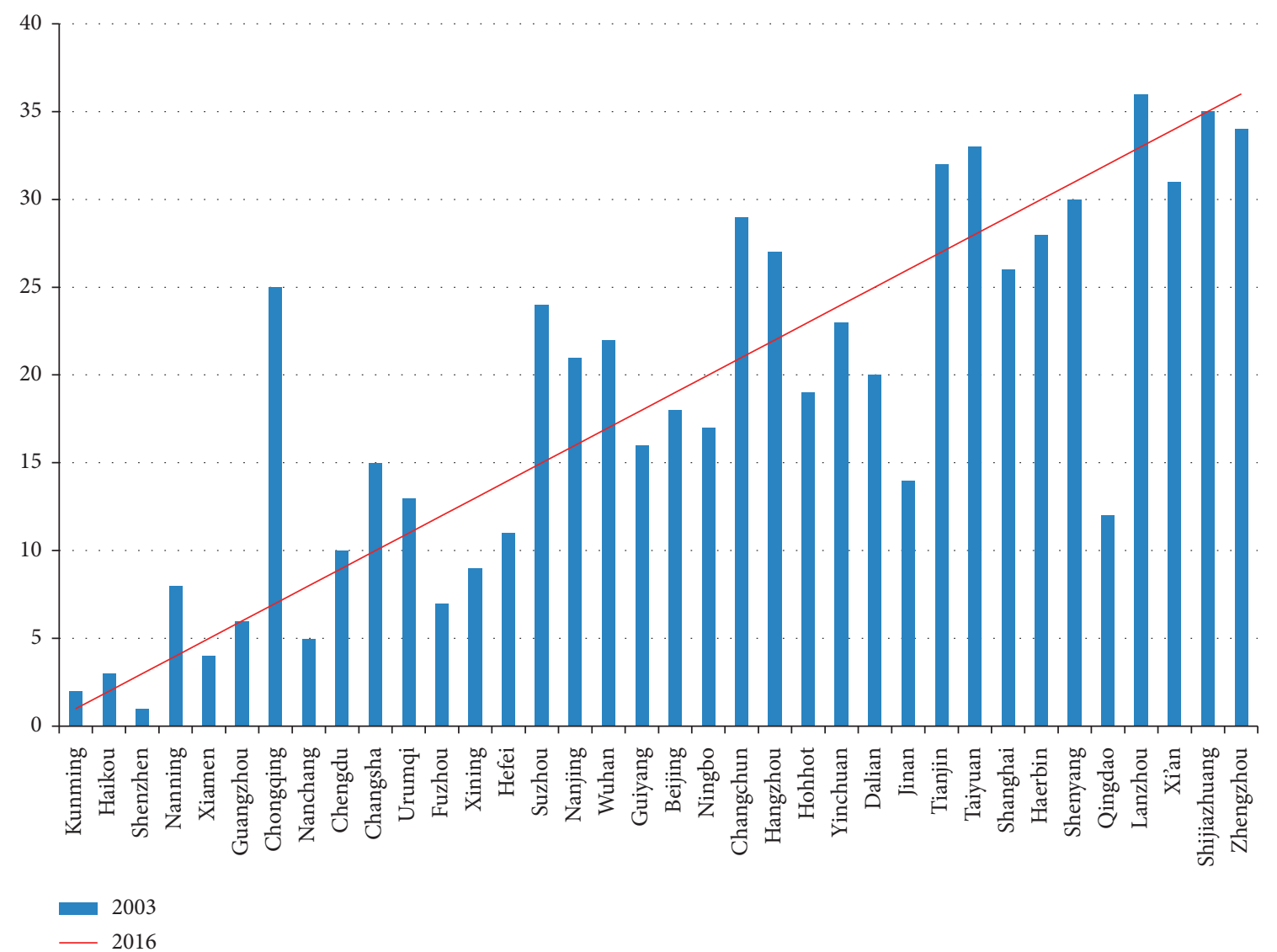

FIGURE 2: Ranking changes of 36 main cities' UPE scores in 2003 and 2016.

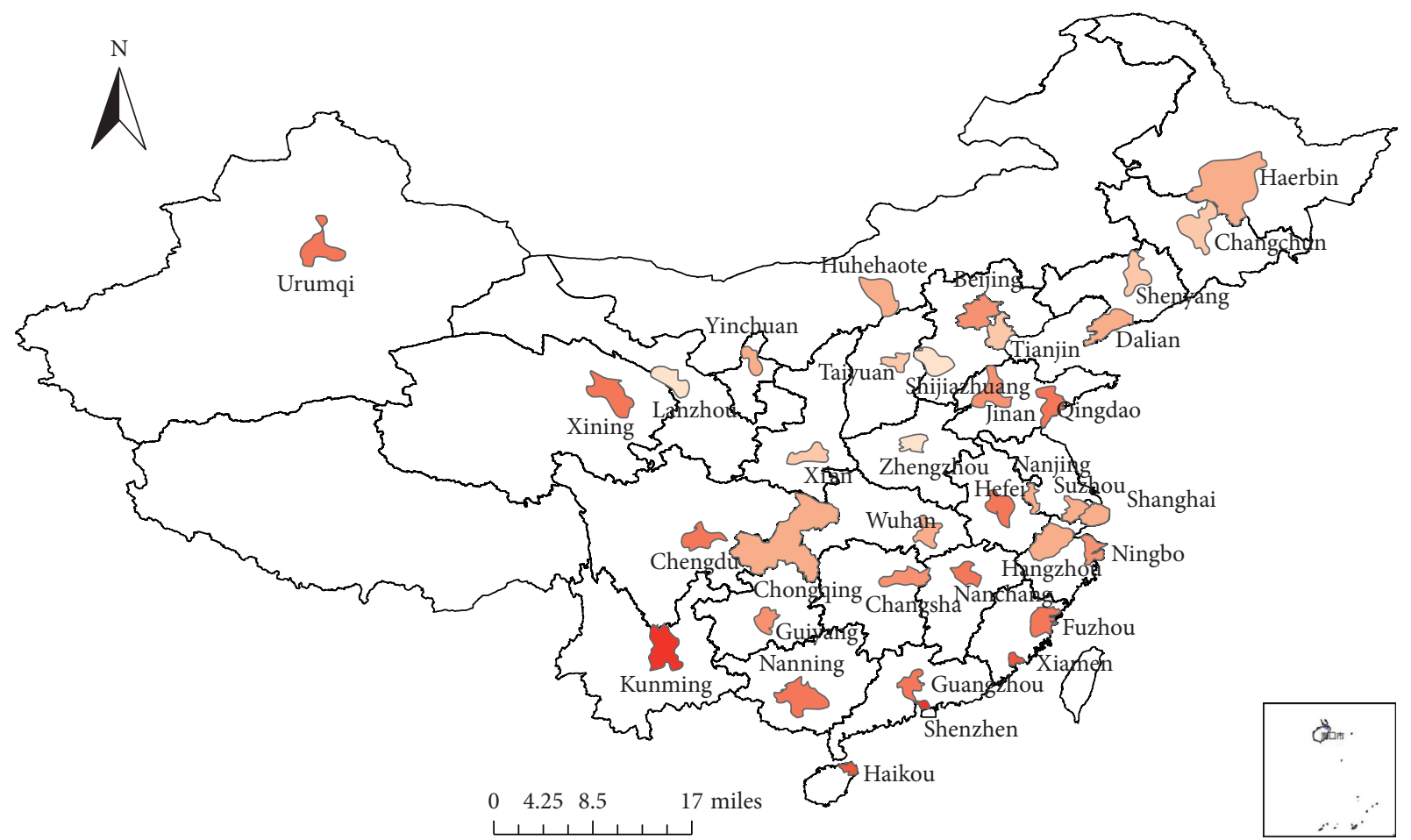



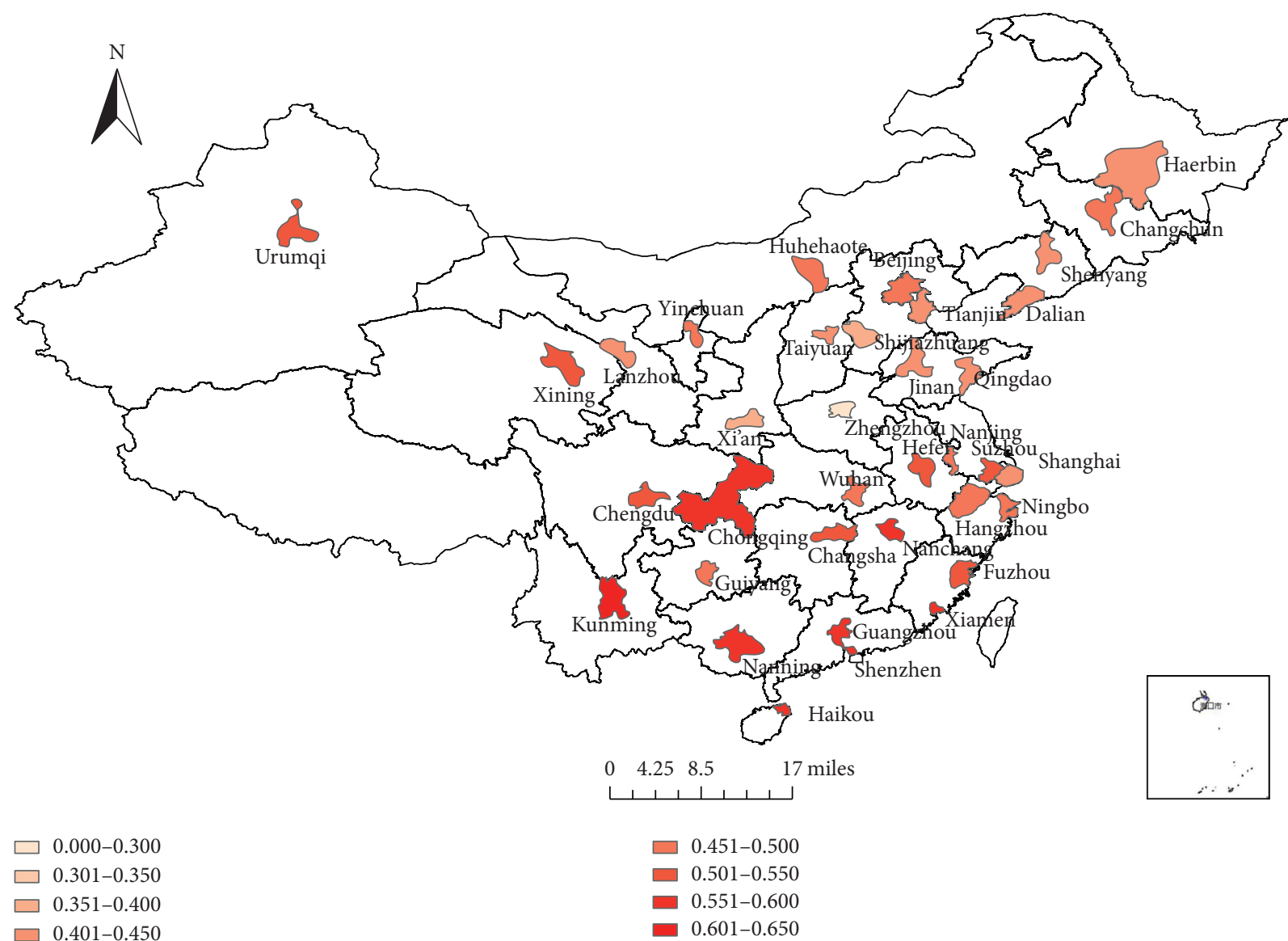

FIgURE 4: Spatial distribution of 36 main cities' UPE scores in 2016.

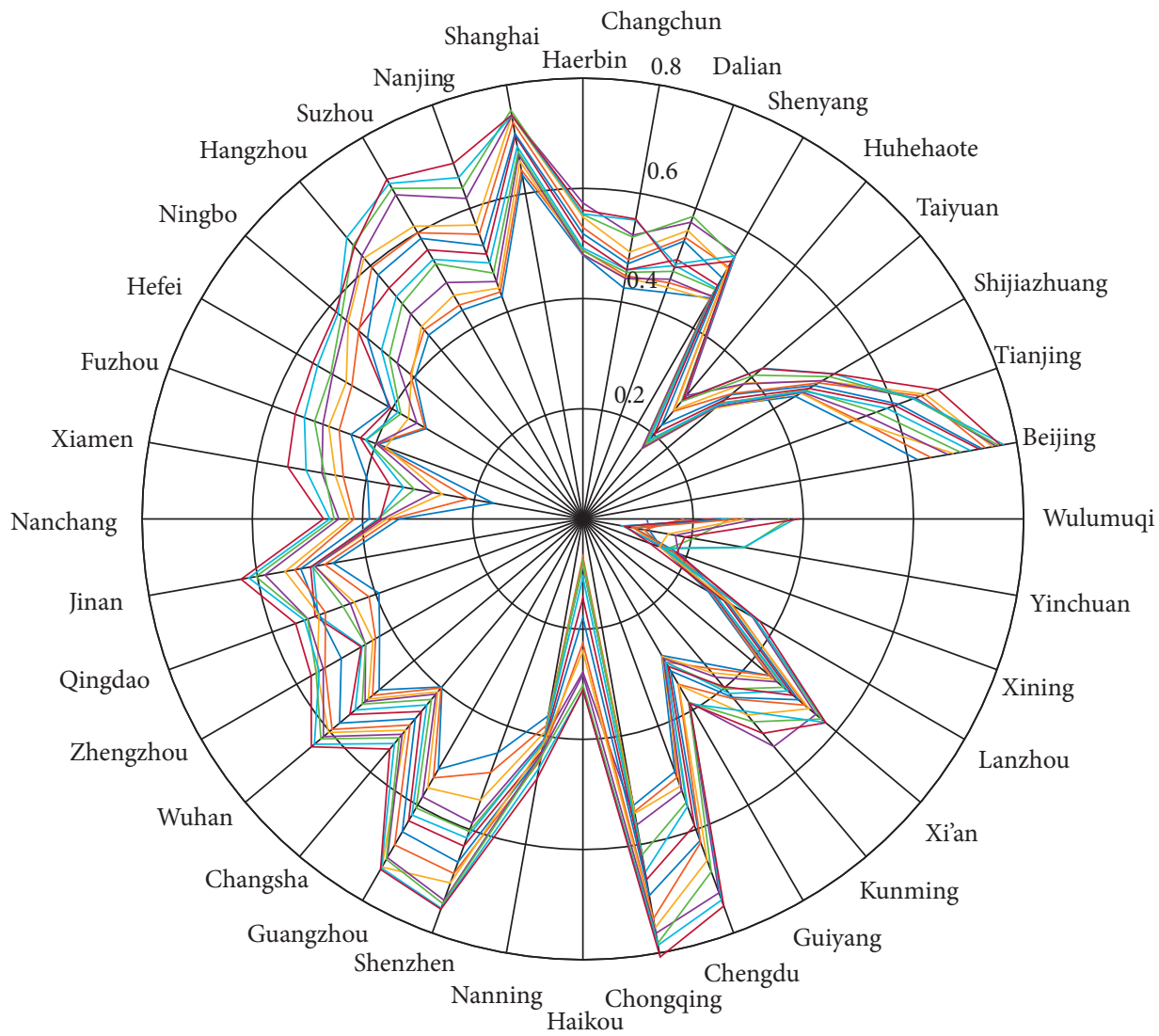

FIgURE 5: Radar diagram of CCD among UPE, economy, and population. 


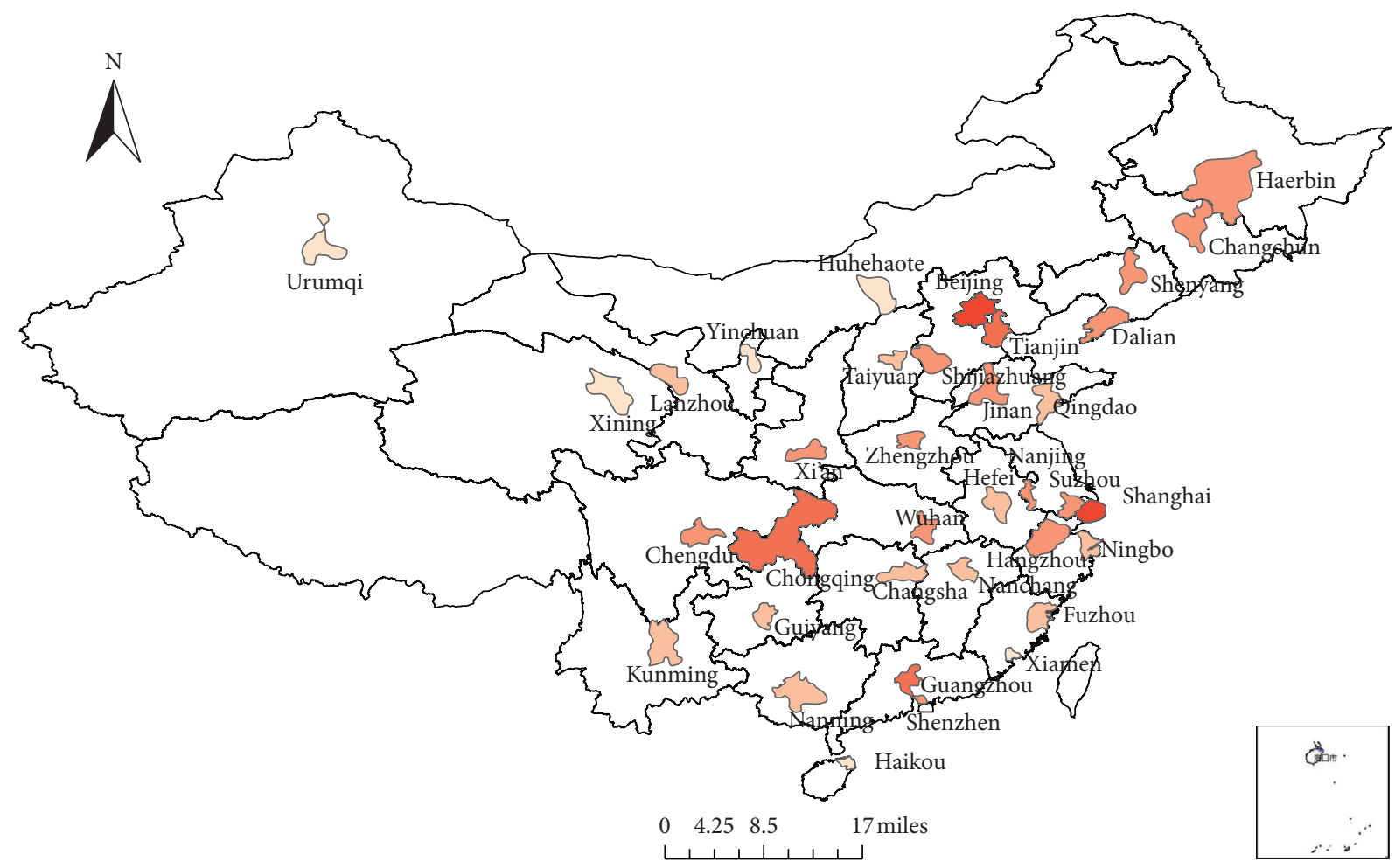

$0.000-0.200$ Seriously unbalanced development

0.201-0.400 Moderately unbalanced development

0.401-0.500 Slightly unbalanced development
0.501-0.600 Barely balanced development

0.601-0.800 Favorably balanced development

0.801-1.000 Superiorly balanced development

Figure 6: Spatial distribution of CCD in UPE, economy, and population in 2003.

unbalanced development" or "slightly unbalanced development." From 2009 to 2016, the CCD score of most cities had reached above 0.5 , and twelve cities reached the stage of "favorable balanced development."

During the 14 years, the CCD scores of the super cities (i.e., Beijing, Shanghai, Shenzhen, and Guangzhou) were in the "favorably balanced development" stage, but the scores of Beijing and Shanghai had little increase after 2011. The specific scores of the three systems revealed that the economic development level and population growth level both exceeded the comprehensive UPE level in those two cities. Chongqing's CCD is of the fastest growing. In 2016, Chongqing became the only city that reached the "superiorly balanced development" phase. A possible explanation for this may be Chongqing has the absolute advantage of attracting immigration as the only municipality directly under the central government in the vast western region of China. Chongqing exhibited a development mode that population gathered, with the UPE improving and economic growth followed by. It should be pointed out that Dalian's CCD score plummeted in 2015; the main cause may be that the Liaoning Provincial Government began to strictly examine and verify the official statistics since 2015, leading to the shrink of Dalian's GDP and population data [33]. Comparing the specific scores of the three subsystems (see Supplementary Materials), the UPE scores of the majority study cities were higher than the scores of economy and population, which illustrated that the main development mode in China was the government invested the infrastructure first, and then introduced industries and attracted population. However, the rapid development of the economy and the continuous accumulation of population placed increasing pressure on the UPE. When the UPE capacity was exceeded, the CCD would stop growing or fall back, just as Beijing and Shanghai.

4.2.2. Spatial Distribution of CCD. The spatial distribution maps of CCD in 2003 and 2016 are shown in Figure 6 and 7. The CCD presented a diversified distribution pattern among different urban agglomerations. For a certain urban agglomeration, the core city takes the high CCD score as the leader. For example, Beijing, Shanghai, Shenzhen, and Chongqing had the highest CCD scores in the four urban agglomerations of Beijing-Tianjin-Hebei, the Yangtze River Delta, the Pearl River Delta, and the Chengdu-Chongqing, respectively. The CCD scores of the cities in the northwest (Yinchuan, Xining, and Urumqi) and northeast (Shenyang, Changchun, Harbin, and Dalian) were generally at a lower level. With the comparison of Figures 6 and 7, the growth rates of CCD in those two regions were much lower than the cities in the south during the 14 years, and the gap was widening. However, the reasons for the poor CCD of the two regions may be slightly different. The comprehensive UPE 


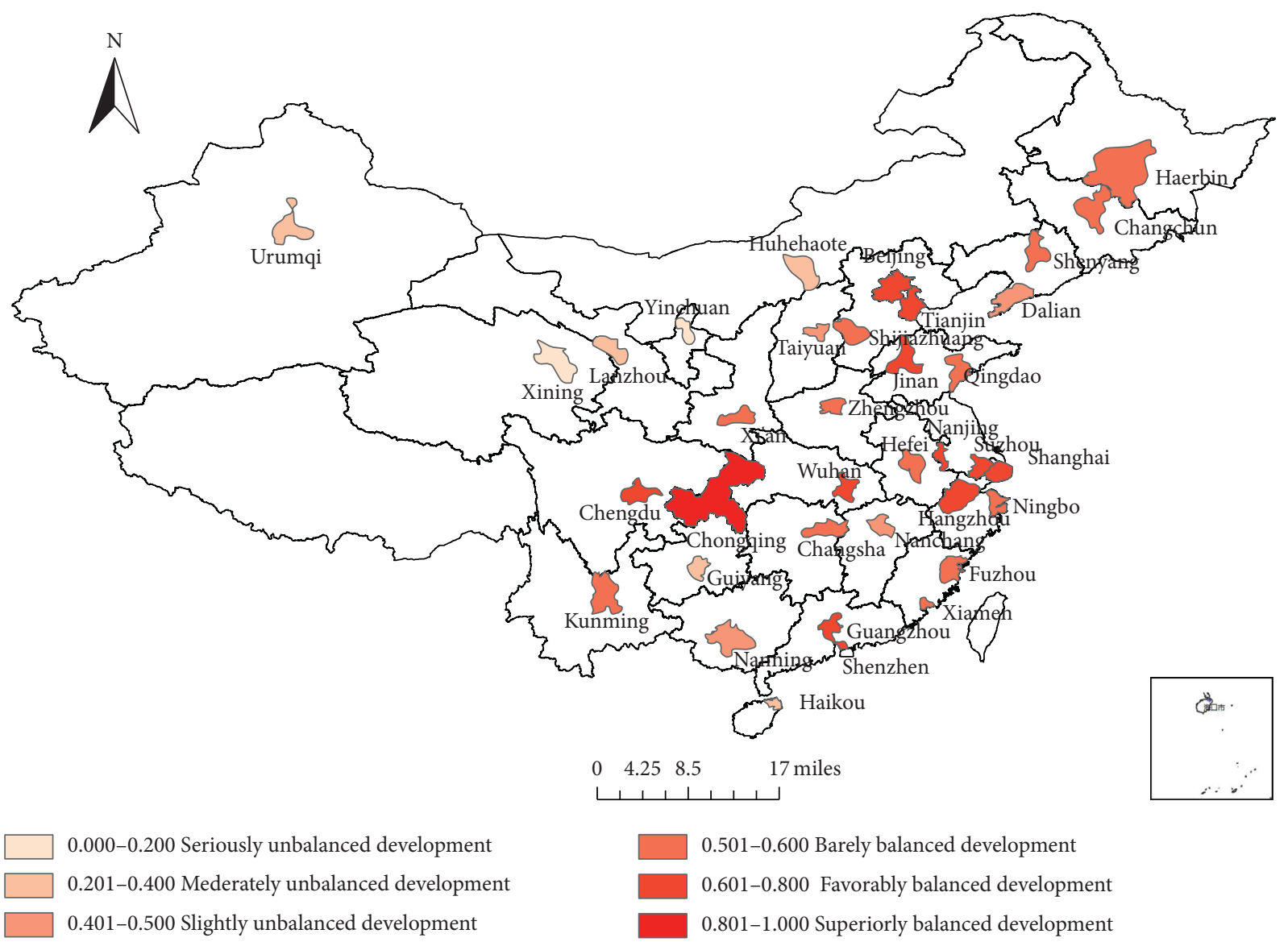

Figure 7: Spatial distribution of CCD in UPE, economy, and population in 2016.

scores of the cities in northeast China (Shenyang, Changchun, and Harbin) were at a medium level, but their climate scores were at the lowest level among all study cities because of the extremely cold climate, which probably results in the large population migration; for example, Harbin had experienced population loss, which was rare in all the study cities. The reason for the poor CCD in the northwestern region (Yinchuan, Xining, and Urumqi) should attribute to the joint action of the poor economic foundation and weak centripetal force of population gathering. The CCD of Xining, Hohhot, and Yinchuan had not made significant progress, especially Xining, which was always in the "seriously unbalanced development" stage during the study period.

\section{Conclusions and Discussion}

During the last two decades, most of the Chinese cities have experienced a rapid development process. The economic development, population growth placed increasing pressure on the urban environment. Under the background of rapid urbanization, the UPE index system and the triple CCD model developed in this study make it possible to further study the relationship between UPE, economy, and population. Such empirical work can provide an evidence base for future attempts to achieve more sustainable city development.
The results of this research suggest that the indicator of climate $(27.0 \%)$ made the greatest contribution to the UPE level. The fluctuation of the UPE level mainly attributed to the cyclical changes of climate. The indicator of the built environment weighted the second largest $(25.8 \%)$ in the UPE system. The overall UPE level of the study cities had slightly improved during 14 years, which were mainly resulted from the continuous improvement of the built environment, the improved water quality after 2008 , and the improved air quality after 2013. These results revealed that the changeable climate made the UPE system fragile. Those cities with insufficient natural endowment must pay more attention to the adverse impacts of industrial development and the population expansion on the UPE and adhere to the new road of industrialization to achieve the coordinated development among UPE, economy, and population.

The CCD of 36 cities had generally increased steadily, most of which presented a path of city development, the improvement of UPE drive the industry, and the industry attract the population. However, in certain super cities (i.e., Beijing and Shanghai), the economy and population development exceeded the carrying capacity of the UPE. This result suggests that most of China's main cities still have a considerable room of the UPE system, but the government should recognize the capacity limitation of the UPE and strive to reduce the environmental impact of the population agglomeration and economic growth by enforcing reduction 
pollution. Meanwhile, some measures must be taken to increase the capacity of the UPE, such as increasing housing supply, improving public transportation systems, and so on.

The CCD of the study cities showed obvious regional differences. In general, the southern cities were of better coupling coordination than the northern cities. Due to the relatively backward economy and slowly growing population, the coupling coordination of both northwest and northeast regions improved slowly. Our findings implicated these cities should seize the opportunity of the national strategy to promote balanced development. As the node cities of the new Silk Road, the northwest cities including Xi'an, Lanzhou, Xining, and Urumqi should take full advantage of the One Belt One Road strategy to develop the economy. The cities located in the northeast region should fully utilize the preferential policies of Northeast Revitalization to promote the reflow of high-quality population.

\section{Data Availability}

The raw data used to support the findings of this study are available from the corresponding author upon request.

\section{Conflicts of Interest}

The authors declare that they have no conflicts of interest.

\section{Acknowledgments}

This work was supported by the Ministry of Housing UrbanRural Development of China (2018R2024) and the Practice and Innovation Fund for University Students of Jiangsu Province (201910304039Z).

\section{Supplementary Materials}

Table 1: weights of the UPE system; Table 2: weights of economic and population system; Table 3: comprehensive scores of the UPE system; Table 4: comprehensive scores of the economic system; Table 5: comprehensive score of the population system; and Table 6: the scores of CCD among UPE, economy, and population. (Supplementary Materials)

\section{References}

[1] J. Luo, X. Zhang, Y. Wu, J. Shen, L. Shen, and X. Xing, "Urban land expansion and the floating population in China: for production or for living?"” Cities, vol. 74, pp. 219-228, 2018.

[2] G.-Y. Cao, G. Chen, L.-H. Pang, X.-Y. Zheng, and S. Nilsson, "Urban growth in China: past, prospect, and its impacts," Population and Environment, vol. 33, no. 2-3, pp. 137-160, 2012.

[3] J. Shang, P. Li, L. Li, and Y. Chen, "The relationship between population growth and capital allocation in urbanization," Technological Forecasting and Social Change, vol. 135, pp. 249-256, 2018.

[4] R. Black, W. N. Adger, N. W. Arnell, S. Dercon, A. Geddes, and D. Thomas, "The effect of environmental change on human migration," Global Environmental Change, vol. 21, pp. S3-S11, 2011.
[5] B. Cao, K. Fu, J. Tao, and S. Wang, "GMM-based research on environmental pollution and population migration in Anhui province, China," Ecological Indicators, vol. 51, pp. 159-164, 2015.

[6] L. Wang, J. Shen, and C. K. L. Chung, "City profile: Suzhou-a Chinese city under transformation," Cities, vol. 44, pp. 60-72, 2015.

[7] S. L. Handy, M. G. Boarnet, R. Ewing, and R. E. Killingsworth, "How the built environment affects physical activity," American Journal of Preventive Medicine, vol. 23, no. 2, pp. 64-73, 2002.

[8] R. Ewing, "Can the physical environment determine physical activity levels?," Exercise and Sport Sciences Reviews, vol. 33, no. 2, pp. 69-75, 2005.

[9] J. Xu, H. Fan, D. Li, J. Deyu, and W. Linlin, "On analysis of the increased reasons and control measure on the PM10 pollution in Dalian city," Environment and Sustainable Development, vol. 40, no. 3, pp. 129-131, 2015, in Chinese.

[10] B. M. dos Santos, L. P. Godoy, and L. M. S. Campos, "Performance evaluation of green suppliers using entropy-TOPSISF," Journal of Cleaner Production, vol. 207, pp. 498-509, 2019.

[11] Y. Li, Y. Li, Y. Zhou, Y. Shi, and X. Zhu, "Investigation of a coupling model of coordination between urbanization and the environment," Journal of Environmental Management, vol. 98, pp. 127-133, 2012.

[12] J. Lu, H. Chang, S. Zhao, and C. Xu, "The evolution of coupling relationship among energy, economy and environment in Shandong province," Economic Geography, vol. 36, pp. 42-48, 2016, in Chinese.

[13] Z. Tang, "An integrated approach to evaluating the coupling coordination between tourism and the environment," Tourism Management, vol. 46, pp. 11-19, 2015.

[14] A. Quinn, D. Vlahov, D. Ompad, and S. Galea, "Physical urban environment," in Encyclopedia of Environmental Health, J. O. Nriagu, Ed., pp. 526-535, Elsevier, Burlington, NJ, USA, 2011.

[15] A. V. Diez Roux and C. Mair, "Neighborhoods and health," Annals of the New York Academy of Sciences, vol. 1186, no. 1, pp. 125-145, 2010.

[16] C. J. Shultz, L. D. Garey, E. V. Schultz, G. T. Stano, R. J. Blakeslee, and S. J. Goodman, "Integration of the total lightning jump algorithm into current operational warning environment conceptual models," in Proceedings of the AMS Annual Meeting, American Meteorological Society, Atlanta, Georgia, February 2014.

[17] Z. Pingyu, S. Fei, L. He, and S. Qiu, "Coordination degree of urban population, economy, space, and environment in shenyang since 1990," China Population, Resources and Environment, vol. 18, no. 2, pp. 115-119, 2008.

[18] L.-Y. Shen, J. Jorge Ochoa, M. N. Shah, and X. Zhang, "The application of urban sustainability indicators-a comparison between various practices," Habitat International, vol. 35, no. 1, pp. 17-29, 2011.

[19] R. McLeman, "Developments in modelling of climate changerelated migration," Climatic Change, vol. 117, no. 3, pp. 599-611, 2012.

[20] H. Lu, J. Wen, and W. Xu, Research on the Effects of Climate Change on Population Mobility in China, pp. 77-84, China Academic Journal Electronic Publishing House, Beijing, China, 2017, in Chinese.

[21] M. Chang, C. Dereczynski, M. A. V. Freitas, and S. C. Chou, "Climate change index: a proposed methodology for assessing susceptibility to future climatic extremes," American Journal of Climate Change, vol. 3, no. 3, pp. 326-337, 2014. 
[22] P. Zhang, J. Zhang, and M. Chen, "Economic impacts of climate change on agriculture: the importance of additional climatic variables other than temperature and precipitation," Journal of Environmental Economics and Management, vol. 83, pp. 8-31, 2017.

[23] S. Peteris, S. Andrejs, K. Galina, and S. Janis, "Potential of solar cooling in Latvian conditions," Energy Procedia, vol. 57, pp. 2629-2635, 2014.

[24] J. T. Houghton, L. G. Meiro Filho, B. A. Callander, N. Harris, A. Kattenburg, and K. Maskell, Climate Change 1995: The Science Of Climate Change, pp. 367-368, Cambridge University Press, Cambridge, UK, 1996.

[25] M. Meng, J. Ni, and Z. Zhang, "Aridity index and its applications in geo-ecological study," Chinese Journal of Plant Ecology, vol. 28, no. 6, pp. 853-861, 2004, in Chinese.

[26] X. Zhang, D. Yang, and W. Ni, "The potential evapotranspiration (PE) index for vegetation and vegetation-climatic classification (III): an introduction of main methods and PEP program," Chinese Journal of Plant Ecology, vol. 17, pp. 97109, 1993, in Chinese.

[27] Y. Liu, C. Yao, G. Wang, and S. Bao, "An integrated sustainable development approach to modeling the eco-environmental effects from urbanization," Ecological Indicators, vol. 11, no. 6, pp. 1599-1608, 2011.

[28] Q. Han, X. Xu, and W. Chang, "Study on city's ecological environment and assessment index system of sustainable development," Environmental Protection Science, vol. 31, pp. 52-55, 2005, in Chinese.

[29] Z. Zhang, J. Liu, and X. Gu, "Reduction of industrial land beyond Urban Development Boundary in Shanghai: differences in policy responses and impact on towns and villages," Land Use Policy, vol. 82, pp. 620-630, 2019.

[30] X. Wang, D. Jiang, and X. Lang, "Future extreme climate changes linked to global warming intensity," Science Bulletin, vol. 62 , no. 24 , pp. $1673-1680,2017$.

[31] National Bureau of Statistics of China, "China Statistical Yearbook 2008," National Bureau of Statistics of China, Beijing, China, 2008

[32] X. Wang, Z. Dong, J. Zhang, and L. Liu, "Modern dust storms in China: an overview," Journal of Arid Environments, vol. 58, no. 4, pp. 559-574, 2004.

[33] The release of GDP data for 31 provinces: Liaoning shrank bymore than 600 billion yuan, 2017, in Chinese, https://www. yicai.com/video/5232162.html. 


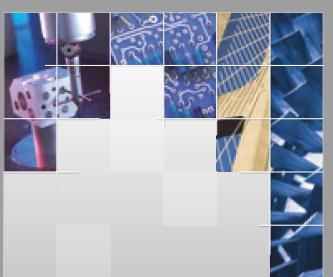

\section{Enfincering}
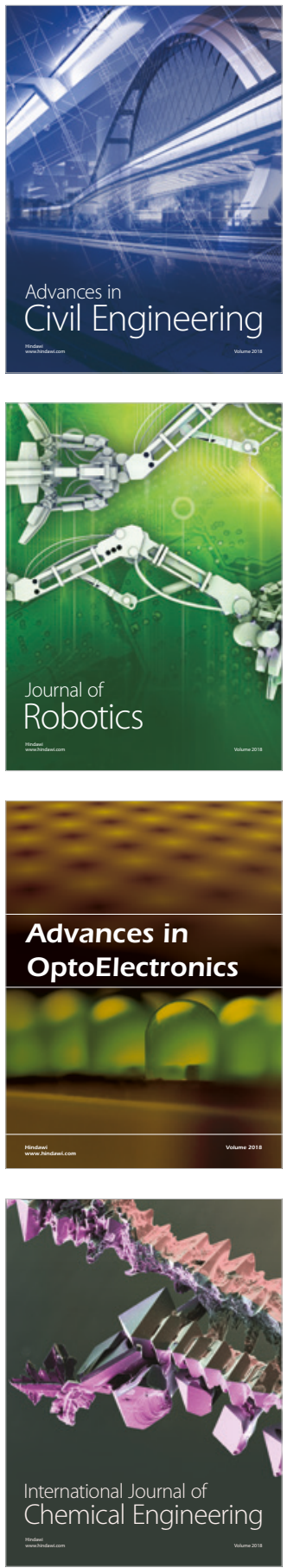

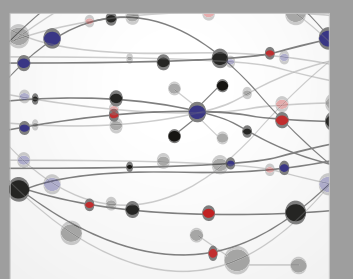

\section{Rotating \\ Machinery}

The Scientific World Journal

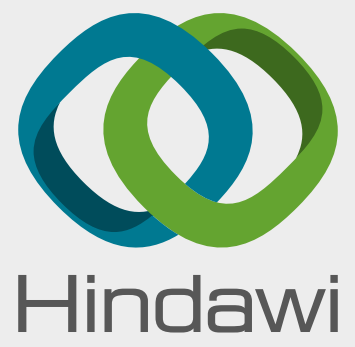

Submit your manuscripts at

www.hindawi.com
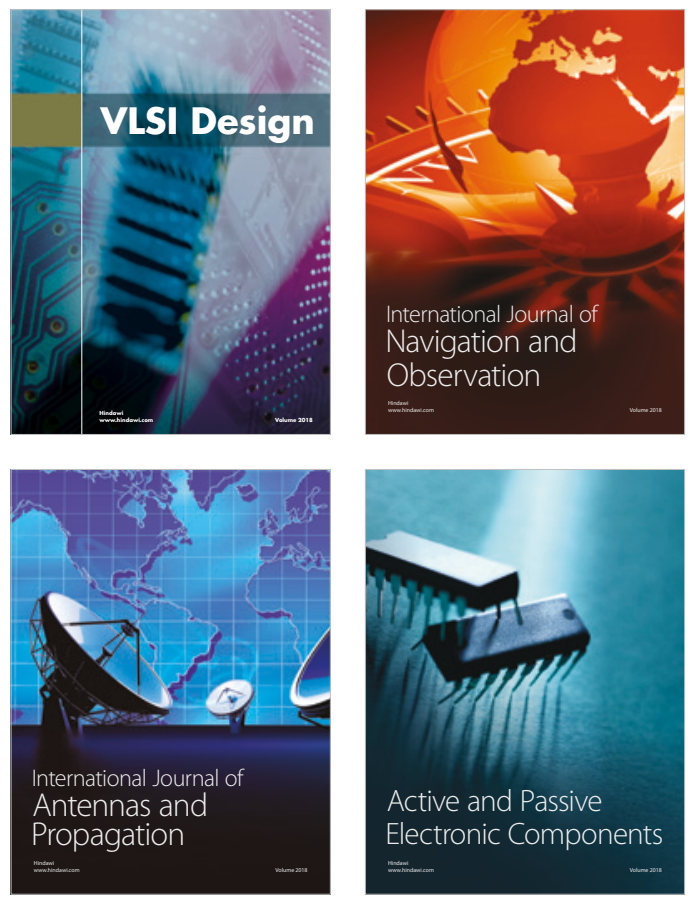
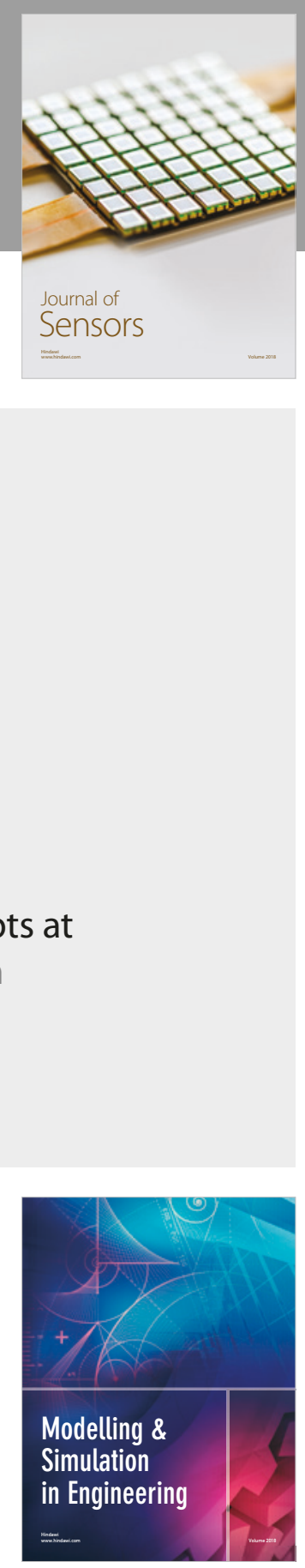

\section{Advances \\ Multimedia}
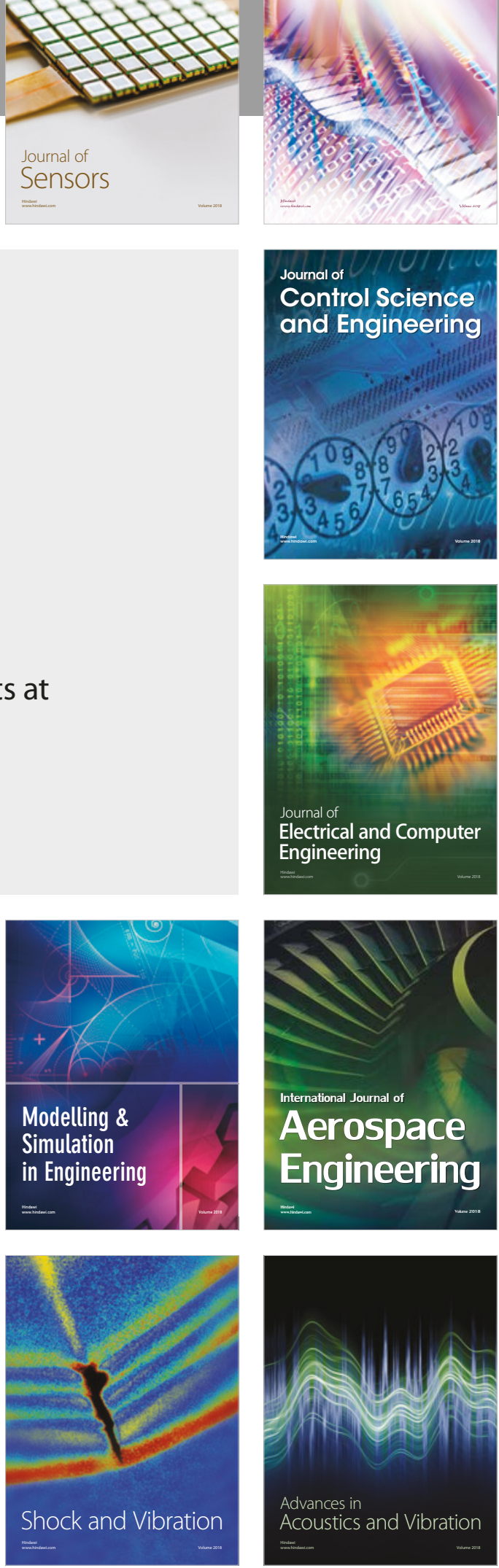